\title{
ENTRE A ENCRUZILHADA E A NEBULOSA: ETNOGRAFIAS PARA PENSAR O SINCRETISMO
}

\author{
Adriane Luisa Rodolpho ${ }^{1}$
}

Resumo: $\mathrm{O}$ texto propõe-se a retomar três etnografias em duas manifestações religiosas, Quimbanda e Eckankar, pertencentes ao universo das religiōes afrobrasileiras e ao movimento da Nova Era, respectivamente. Nesse exercício de reflexão sobre pesquisas realizadas em momentos diferentes (no Brasil e na França), proponho-me a discutir o conceito de sincretismo em meus trabalhos, tomando como interlocutor privilegiado Pierre Sanchiz e suas ideias sobre o tema, na obra por ele organizada Fiéis e Cidadãos. Percursos de Sincretismo no Brasil, de 2001.

Palavras-chave: Sincretismo; Religióes Afro-Brasileiras; Nova Era.

Abstract: The text aims to review three ethnographies in two religious movements: Quimbanda and Eckankar. The former is part of the universe of Afro-Brazilian religions and the latter belongs to the New Age movement. In this exercise of reflection about researches conducted in different moments (in Brazil and in France), I want to discuss the concept of syncretism in my papers, having as my privileged interlocutor Pierre Sanchis as well as the work organizes by him in 2001 Fiéis e Cidadãos. Percursos de Sincretismo no Brasil.

Keywords: Syncretism; Afro-Brazilian Religions; New Age.

Ao refletir sobre a questão do sincretismo para a elaboração deste artigo, percebo que em minha dissertação de mestrado e na tese de doutorado lancei mão de outras noções teóricas alternativas a esse conceito, tanto com relação à etnografia realizada junto às religiões afro-brasileiras (a encruzilhada) quanto nas relativas ao movimento da Nova Era (a nebulosa). Assim, em cada uma daquelas circunstâncias específicas de pesquisa, ao invés de realizar

${ }^{1}$ Professora do Departamento de Antropologia e Arqueologia da UFPel. 
uma discussão específica sobre o conceito de sincretismo, percebo que essa discussão foi tangenciada nos desenvolvimentos de ambos os trabalhos. Por algum motivo, busquei conceitos correlatos, apesar de considerar que a noção de sincretismo pode, sim, ser heuristicamente frutífera.

Talvez, nos dois universos de pesquisa nos quais me inseri, o interesse em buscar e conhecer alternativas outras ao conceito de sincretismo possa ter sido fruto de minha necessidade de aprofundar outros conceitos antropológicos que não parecessem tão conhecidos, examinados, discutidos e, por isso mesmo, menos passíveis de abordagens diversas e por vezes conflituosas, como ocorre com o conceito de sincretismo. De fato, a opção em tomar tal conceito como ferramenta analítica é menos um fator ligado à noção do senso-comum, que associa o sincretismo apenas a uma redução em síntese de múltiplos elementos, do que o fato de que o conceito tenha uma longa história entre os analistas do campo religioso. Concordo com Pierre Sanchis quando esse afirma que:

Quem sabe o fato de encontrar o sincretismo - em formas abertamente vivenciadas ou como jazida encoberta a ser analiticamente explorada - no decorrer de pesquisas que não almejavam de antemão abordá-lo, não pode contribuir para lhe esclarecer o sentido? (Sanchis, 2001, p. 10)

Uma breve retomada dessas pesquisas realizadas já há alguns anos pode ser um exercício útil para, a posteriori, refletir sobre as "formas vivenciadas" às quais o autor acima se refere, contribuindo para a discussão de forma mais ampla. A análise aqui proposta leva em consideração tanto o recorte relativo aos campos religiosos, brasileiro e francês, - onde foram realizadas as etnografias - quanto à noção de pessoa (Mauss, 2001), desenvolvidas junto aos participantes das religiōes afro-brasileiras e de movimentos da Nova Era. A noção de pessoa foi um dos conceitos norteadores de ambas as pesquisas e o será igualmente nesse exercício de reflexão sobre o sincretismo. 


\section{SINCRETISMO: O CAMPO E A PESSOA NA QUIMBANDA}

Em minhas experiências etnográficas, deparei-me com diversas noçôes sobre o sincretismo quando da pesquisa sobre a umbanda cruzada ou quimbanda no Rio Grande do Sul (Rodolpho, 1984); nesse caso, o tema era recorrente entre uma série de pesquisadores, em função de características próprias a essa forma de culto e à própria historiografia sobre o tema ${ }^{2}$.

A dissertação versava sobre o ritual do sacrifício de animais no âmbito da Umbanda Cruzada ou Quimbanda e se propunha a perceber uma noção de pessoa ao mesmo tempo múltipla e singular, uma vez que a lógica da identidade e da diferença, em minha opinião, eram operacionalizadas pelo grupo em questão de forma particular.

O sacrifício, considerado como uma matriz hermenêutica junto ao transe de possessão, aparecia igualmente como um ponto de observação privilegiado para a percepção de um ethos e de uma visão de mundo partilhados pelos participantes dessa manifestação religiosa (Geertz, 1978). O ritual do sacrifício atualiza, ao lado do transe de possessão, a identidade da pessoa no universo das religiões afro-brasileiras, que experimenta o contato com seu orixá (uma divindade) e com suas entidades (espíritos de Caboclos, Pretos-Velhos, Exus e Pombagiras) em um mesmo corpo, em momentos diferentes. $\mathrm{Na}$ cosmologia afro-brasileira, as relações entre os adeptos e o panteão de categorias diferentes de espíritos expressa-se no dia a dia do fiel.

Nessa dinâmica, utilizei-me de um referencial teórico ancorado na escola francesa, a partir de Marcel Mauss e Lévi-Strauss, e igualmente inspirada pelos brasileiros Márcio Goldman e Eduardo Viveiros de Castro. O exercício de reflexão proposto na dissertação igualmente foi o responsável pela opção de utilizar-me de um conceito desenvolvido por um colega de mestrado, à época. De fato, em sua dissertação de mestrado José Antônio Gomes dos Anjos (Anjos, 2006) propunha uma alternativa ao conceito de sincretismo: a noção de encruzilhada tomada a partir do modelo de rizoma de Deleuze (utilizo-me da versão publicada da dissertação para as citações).

2 No livro Repensando o Sincretismo, de 1995, Sérgio Figueiredo Ferretti fornece-nos uma excelente revisão da literatura sobre o conceito de sincretismo religioso afro-brasileiro (capítulo 2).

Debates do NER, Porto Alegre, ano i2, N. i9 P. IO7-I2O, Jan./Jun. 201 I 
Falar-se-ia então de uma forma rizomática de pensar e trabalhar as diferenças em oposição ao pensamento arborescente que caracteriza a definição de sincretismo (usual na definição das práticas religiosas africanas no Brasil). (Anjos, 2006, p. 21)

E, na página seguinte,

[...] a lógica rizomática da religiosidade afro-brasileira, ao invés de dissolver as diferenças, conecta o diferente com o diferente deixando as diferenças subsistirem como tais. Um caboclo permanece diferenciado de um orixá mesmo se cultuados no mesmo terreiro e sob o mesmo nome próprio (como, por exemplo, ogum). (Anjos, 2006, p. 22)

Ora, a categoria de encruzilhada, assim como definida por dos Anjos, vinha ao encontro do restante de meu arcabouço teórico, como pode-se perceber pela citação abaixo, copiada de minha dissertação.

Penso que as contribuições de Viveiros de Castro e Anjos permitem uma visão mais ampla sobre a noção de pessoa em curso. O Devir, resolvido de diferentes maneiras entre Arawetés e Povo da Religião, apresenta-se como o ponto para o qual convergem as análises. Diferentemente dos primeiros, a pessoa, aqui, se constrói e se reatualiza no momento presente, no aqui e no agora da situacionalidade: seja étnica, de gênero, familiar ou, com relação especificamente ao nível religioso, nos momentos gradualizados do sagrado, onde a possessão e o sacrifício inscrevem-se como os mais elevados níveis. (Rodolpho, 1994, p. 227)

A argumentação igualmente baseava-se nas análises de Márcio Goldman, para quem “[...] a possessão está intrinsecamente ligada com a 'noção de pessoa’ adotada pelo grupo que a pratica” (Goldman, 1987, p. 95).

Dessa forma, nesta primeira pesquisa, minhas atenções estavam mais voltadas para as características da manifestação religiosa em si e para essa pessoa que se construía ritualmente. Com relação ao campo religioso, revejo que, ainda na Introdução da dissertação, utilizei-me da célebre citação de 
Gilberto Velho sobre a 'crença em espíritos' como uma categoria de análise do panorama cultural brasileiro:

[...] a crença em espíritos, no transe, na mediunidade e na possessão cria uma linguagem básica que não esvazia a importância das diferenças substantivas entre os grupos, com suas identidades e valores particulares. Nessa linguagem, o domínio do 'sobrenatural' aparece como fundamental para compreender o sistema de representaçóes da sociedade brasileira ou do sistema cultural propriamente dito. (Velho, 1994, p. 61).

Olhando retrospectivamente, creio que a imagem do campo religioso brasileiro como extremamente permeável, dinâmico, sincrético e antissincrético ao mesmo tempo, já estava implícito nessa dissertação de 1994, a partir dos autores que escolhi. De fato, do ponto de vista de Anjos, Goldman e Velho, essa estrutura de diálogo constante entre os humanos e os espíritos, forças e os seres de um mundo invisível é uma realidade do campo brasileiro.

Nesse sentido, Pierre Sanchis identifica esse aspecto como uma 'terceira modalidade ${ }^{\prime 3}$ que caracteriza o campo religioso no Brasil contemporâneo. Refiro-me ao "clima espiritualista que parece partilhado e modulado por várias 'mentalidades' segmentárias no Brasil”. Nesse sentido, Sanchis aponta para a construção de um 'habitus ancorado em sociogênese', em que a 'porosidade de identidades e permanência de uma multiplicidade de processos de um sujeito plural' são as duas características principais do campo religioso, em relação sempre dialética. (Sanchis, 2001, p. 26)

Pesa na sociedade brasileira - e não só no campo religioso - a presença de uma predisposição estrutural à porosidade - mas não à confusão - das identidades. (Sanchis, 2001, p. 25)

3 Primeira modalidade: hipótese de 'existência generalizada ao cristianismo, talvez mais ainda ao catolicismo'. (Sanchis, 2001, p. 19); segunda modalidade: 'catolicismo como estrutura virtualmente sincrética'. (Sanchis, 2001, p. 23) 
Em outro momento, analisando a problemática entre o catolicismo e as religiōes afro-brasileiras a partir do texto sobre os Agentes de Pastoral Negros (Sanchis, 1999), o autor é bastante sintético em sua definição do conceito de sincretismo:

[...] um caso paradigmático e consciente do sincretismo tal como pensamos que se poderia definir: a transformação de elementos da própria identidade em função do encontro com o outro. (Sanchis, 1999, p. 65).

Nessa acepção, o sincretismo apresenta-se como atravessando tanto o campo religioso quanto as identidades, num processo constante de negociações, redefinições e trocas com o outro. No caso dos participantes das religiōes afro-brasileiras, esse 'processo estrutural sincrético' a que se refere Sanchis, percebe-se nos inúmeros rituais aos quais os filhos de santo se dedicam ao longo de suas vidas, na noção de pessoa que se constrói em comunicação constante com o mundo invisível. O corpo é o locus desses encontros, multiplicidade que não confunde as identidades do caboclo, exu ou orixá, como salientado mais acima.

Penso que a utilização, à época, do conceito de encruzilhada feita por Anjos (2006) foi uma opção adequada, e isso não significa que a reflexão sobre o conceito de sincretismo que agora realizo invalide aquele. Pelo contrário, exercitando esse paralelismo, observamos que a noção de pessoa, eixo da discussão, constrói-se exatamente nesse encontro com o outro (com seu orixá e suas entidades - com o seu Devir) ${ }^{4}$.

\section{SINCRETISMO: O CAMPO E A PESSOA EM ECKANKAR}

Num segundo momento, por ocasião do doutorado, tive a oportunidade de trocar, radicalmente, de campo religioso e de universo de pesquisa. Em Paris, desenvolvi durante os anos de 1997-2002 uma pesquisa junto a um

${ }^{4}$ Lembramos que durante os rituais de sacrifícios são realizadas as iniciações, no Batuque e na Umbanda Cruzada ou Quimbanda; durante estes ciclos rituais, o fiel João da Silva se torna João do Xangô. 
grupo religioso participante do movimento de Nova Era, chamado Eckankar (Rodolpho, 2002; 2010).

O grupo Eckankar participa dos assim chamados novos movimentos religiosos ou, ainda, da nebulosa mistico-esotérica5 (Champion, 1993; 2001), tendo como características principais uma doutrina espiritualista que promove a prática da 'viagem da alma'. Meditação e canto permitem aos adeptos a experiência de deslocamento espacial da alma, quando essa acessa (ou viaja) para outros planos e dimensōes espirituais. Organizada por um antigo cientólogo e autor de ficção-científica chamado Paul Twitchell, o grupo inicia suas atividades nos Estados Unidos em 1965 e apresenta rápida expansão para Canadá, África e Europa.

Naturalmente, a própria classificação do grupo Eckankar como inserido no movimento de Nova Era, era fruto de meu raciocínio que tinha, ainda, como pano de fundo cultural e religioso a realidade brasileira. Além disso, aos olhos de uma antropóloga brasileira, Eckankar enquadrava-se na definição de Leila Amaral a respeito dos participantes desse movimento:

Com a expressão Nova Era, estarei referindo-me a um campo de discursos variados, mas em cruzamento, por onde passam: a) os herdeiros da contracultura com suas propostas de comunidades alternativas; b) o discurso do autodesenvolvimento, na base das propostas terapêuticas atraídas por experiências místicas e filosofias holistas, fazendo-as corresponder às modernas teses de divulgação científica; c) os curiosos do oculto, informados pelos movimentos esotéricos do século XIX e pelo encontro com as religiôes orientais, populares e indígenas; d) o discurso ecológico de sacralização da natureza e do encontro cósmico do sujeito com sua essência e perfeição interior, e e) a reinterpretação yuppie dessa espiritualidade centrada na perfeição interior, através dos serviços new-age oferecidos para o treinamento de recursos humanos, nas empresas capitalistas. (Amaral, 1999, p. 01).

${ }^{5}$ A nebulosa místico-esotérica realiza-se, basicamente, pela centralidade concedida à experiência, pela transformação pessoal e por uma concepção monista da realidade. (Champion, 2001) 
$\mathrm{Na}$ França, entretanto, o grupo Eckankar foi incluído como seita na lista do Relatório da Assembleia Nacional de 1995, e a especificidade do campo religioso francês distingue claramente essa categoria da esfera das religiões institucionalizadas. Nesse sentido, relembro Patrícia Birman, quando essa afirma que:

O sincretismo e a tolerância religiosa do lado brasileiro e o anti-sincretismo e a intolerância religiosa do lado francês resumem o essencial dessa diferença, vista em seus traços mais largos, em certa medida tipificados e, por isso, um tanto enganadores. Tais contrastes excessivos precisam ser desconstruídos a partir de uma mesma questão: que lugares e sentidos o 'religioso' está assumindo aqui e lá? (Birman apud Sanchis, 2001, p. 59)

De fato, a inclusão de Eckankar entre as seitas e a caracterização dos sujeitos, de minha parte, como participantes do movimento da Nova Era foi um eixo da pesquisa que se constituiu como o pano de fundo da discussão. A especificidade do campo religioso francês, distinguindo seitas e religiōes, influiu diretamente no objetivo inicial da pesquisa, que era a de realizar uma etnografia baseada na antropologia visual. (Rodolpho, 2003)

Nessa ocasiāo, entre tantos outros, os referenciais teóricos desenvolvidos por Marcel Mauss e Clifford Geertz foram novamente acionados, e procurei perceber de que maneira a noção de pessoa construída pelos adeptos de Eckankar se coadunava com suas noções de visão de mundo e ethos. Assim, mesmo numa sociedade como a francesa, em que o campo religioso pode ser caracterizado, sobretudo, como relativo à esfera da vida privada e por uma ênfase em valores mais individualistas, encontramos os membros de Eckankar realizando cotidianamente suas trocas e relações com o mundo dos espíritos.

De fato, é interessante relembrar especificamente a situação parisiense do grupo em questão. Como capital que congrega um grande número de imigrantes vindos de todas as partes, um eckista vindo do Bénin me chamava a atenção para esse traço: Eckankar em Paris é diferente com relação à Eckankar nas cidades do interior da França. Com o passar do tempo, percebi que os eckistas africanos faziam referência a inúmeros temas como a existência de 
marabouts (feiticeiros) circundantes. Essas propostas trazidas pelos eckistas originários do Bénin, Togo e de imigrantes de outras nações africanas francófonas $^{6}$ eram incorporadas à doutrina eckista de forma criativa.

Alguns eckistas tinham, portanto, consciência de que suas contribuições não estavam de todo adequadas à comunidade eckista mais ampla (tanto no interior do país quanto nos Estados Unidos, no Canadá ou em países europeus), mas realizavam um verdadeiro trabalho sincrético entre as suas concepçôes de origem e a cosmologia Nova Era proposta por Eckankar, e isso de forma não contraditória e não conflitante. O exemplo dos marabuts tidos como feiticeiros agindo no cotidiano era relatado por um eckista togonês, que me explicava que a energia do Mahanta, o Mestre Eck, era superior a todas as outras. Se a sua concepção original de forças invisíveis capazes de atingi-lo negativamente não havia se modificado, agora ele contaria com um recurso a mais em sua luta por proteção diária: o canto do Hu e a viagem da alma.

A noção de pessoa foi igualmente um conceito-chave no desenvolvimento da etnografia realizada em Paris junto ao grupo Eckankar. Em suas narrativas, os eckistas lembravam seus passados de crianças educadas no catolicismo, de forma mais ou menos intensa (entre canadenses, africanos, franceses e europeus constituintes do grupo Eckankar-Paris). Entre os entrevistados, algumas pessoas relataram terem estudado em escolas ou vivido em pensionatos católicos. Ou seja, de católicos praticantes foram, paulatinamente, transitando para outros horizontes de sentido. Todos salientaram suas identidades de pesquisadores-espirituais, de pessoas que muito procuraram, estudaram e experimentaram (sobretudo) várias possibilidades de filosofias e doutrinas.

Os eckistas são igualmente pessoas providas de uma bagagem cultural cristã, esotérica e mística remarcáveis; assim, a denominação de pesquisadores espirituais ajuda a caracterizar suas trajetórias de vida, um percurso onde predomina a busca de sistemas de crenças e de grupos de prática espirituais. $\mathrm{O}$ fato de que a maioria entre eckistas entrevistados tenham conhecido

${ }^{6}$ É interessante observar que Eckankar se instalou em vários países africanos logo após sua fundação, nos Estados Unidos, em 1965, e no Togo, a partir de 1968. 
Eckankar numa idade madura indica, igualmente, que cada um entre eles havia já conhecido diversas experiências em grupos de crenças alternativas, tais como Teosofia, Meditação Transcendental e grupos orientalistas, entre outros. Percebemos que oriundos de tradições culturais e religiosas diversas, os eckistas de Paris convergem num intenso trabalho de ressignificação de suas trajetórias espirituais anteriores para o encontro com Eckankar'.

A adesão ao sistema de crenças de Eckankar pressupõe de início a aceitação de noções tais como a imortalidade da alma e a reencarnação. Essas ideias fazem parte de concepções popularizadas no Ocidente há muito tempo, e são presentes em várias manifestações religiosas; daí a uma afinidade com os contornos propriamente eckistas destes conceitos a distância não é tão grande.

Um aspecto interessante é a ideia de comunidade espiritual em Eckankar: concordando com Leila Amaral, os eckistas partilham um sentimento de "estar junto" anterior ao "estar com" (Amaral, 200, p. 208). E, de fato, os eckistas afirmavam sempre que podiam realizar suas práticas sozinhos, individualmente, sem necessitar do grupo físico aqui, porque muitos ensinamentos são adquiridos enquanto a pessoa viaja, em sua alma, para outros planos onde a verdadeira comunidade eckista se reúne. Entretanto, pude perceber, durante a etnografia junto ao grupo, que estes se encontravam com muita frequência, inclusive durante as férias, quando são planejados encontros e seminários, nacionais e internacionais. Esses encontros são baseados na leitura dos escritos do fundador do movimento, em que a doutrina propriamente dita é exposta; por outro lado, as reuniōes sempre possuem um espaço para os depoimentos. Nessas ocasiões, os eckistas fazem um trabalho comunitário de trocas de experiências e relatam onde, como e quando o Mahanta, ou Mestre Eck, manifesta-se na vida cotidiana. São momentos fundamentais para se observar o que Sanchis já caracterizava como 'a transformação de elementos da própria identidade em função do encontro com o outro’.

Retomando novamente esse autor, penso que a realidade francesa poderia paralelamente ser pensada nos termos do continuum que Sanchis identifica com relação aos dois polos que indicariam o 'espírito de um novo tempo' (expressão de Gilberto Velho retomada por Sanchis, 2002, p. 33). 
Esses dois 'polos ideal-típicos' compreendem, de um lado, o movimento da Nova Era e, de outro, 'um princípio de equivalência, permitindo que se desfralde sem quadros ou limites um imaginário cultural em que tudo é plausível' - a chamada condição pós-moderna de Paul Heelas (Id.). Neste sentido, a atitude subjetivante e a primazia da emoção são características dos movimentos de Nova Era no qual Eckankar se insere, seja na França ou no Brasil.

\section{SINCRETISMO: O CAMPO E A PESSOA EM ECKANKAR, NO BRASIL}

A terceira experiência etnográfica que eu gostaria de apresentar é a pesquisa sobre o grupo Eckankar que efetuei, por breve tempo, junto a um grupo de Eckistas na cidade do Rio de Janeiro. Essa pesquisa sobre Eckankar no Brasil constituiu-se de poucos encontros, não sendo possível dar continuidade ao trabalho em função de solicitação da direção do grupo na América Latina (Rodolpho, 2008).

Minha inserção em campo deu-se a partir de visitas que ocorreram algumas vezes. A etnografia formalizada e asséptica dos encontros completamente impessoais: é possível superar as distâncias? Nenhum convite para visitar as casas das pessoas, nenhuma entrevista mais longa e, por fim, a solicitação educada por parte da dirigente para a América Latina de Eckankar de não publicizar o nome do grupo que, naquele momento, estava pleiteando o status de organização sem fins lucrativos junto aos órgãos brasileiros competentes.

A posição do pesquisador, em situações de trabalhos de campo, é de constante negociação. Assim, a interrupção da pesquisa junto aos eckistas cariocas apresenta-se como um contraponto interessante à situação francesa, em que a recusa quanto à captação de imagens não implicou um cancelamento do trabalho de campo. Dito de outra forma: era igualmente difícil pesquisar os eckistas, tanto no Brasil como na França. Estes diferentes contextos religiosos de inserção podem indicar semelhanças estruturais a um 
movimento transnacional como Eckankar, tais como a rígida hierarquia e o controle da ortodoxia por parte dessas lideranças.

Entretanto, naqueles breves encontros, tive a oportunidade de conversar com várias pessoas, e um adepto em particular que indicava, novamente, aquele 'habitus ancorado em sociogênese', e a 'porosidade de identidades e permanência de uma multiplicidade de processos de um sujeito plural' a que se referia Sanchis. Ismael - digamos que esse seria seu nome - era um eckista que estava, então, em pleno trabalho sincrético: em nossas conversas Eckankar figurava como o contraponto para várias experiências desse ex-adepto da umbanda, do espiritismo kardecista, dos Rosa-Cruzes e de outros movimentos. Sua trajetória e suas narrativas não se diferenciavam muito das relatadas pelos eckistas que conheci em Paris, ressaltando sempre a busca por conhecimentos e, sobretudo, experiências. A ênfase no caráter emocional dessas experiências era indicadora de validade objetiva: como os eckistas parisienses, Ismael recomendava fazer a "[...] experiência de cantar o $\mathrm{Hu}$, praticar a viagem da alma e comprovar por mim mesma”.

\section{SINCRETISMO: CONSIDERAÇŌEES FINAIS}

Ao fim desta retrospectiva de algumas experiências etnográficas, é possível perceber que vários processos sincréticos estiveram em curso, tanto entre os eckistas em Paris quanto no Rio de Janeiro. Oriundos de campos religiosos bastante diferentes, em termos gerais, pode-se pensar, entretanto, que esses sujeitos se movem num horizonte de crenças permeável e plástico, em que adições pessoais são não apenas possíveis, mas formadoras de sentidos. Neste sentido, a proposta de Sanchis (2001) de analisar a religião através da ótica do sincretismo - fazendo a ressalva que o sincretismo parece ser uma dimensão universal na história das religiões e que, contudo, não pensa encontrá-lo mais no Brasil do que em outras sociedades - parece adequada para pensar em fenômenos contemporâneos de crença, tanto aqui como em alhures.

Numa dimensão comparativa entre os exemplos etnográficos, percebe-se que seria errôneo e superficial concluir que os membros das religiōes afrobrasileiras seriam mais - ou menos - sincréticos que os membros de Eckankar 
de Paris. Igualmente não me parece que o sincretismo possa ser definidor de uma forma específica de religiosidade, entre as duas aqui apresentadas, uma mais - ou menos - sincrética que a outra.

$\mathrm{Na}$ verdade acredito na pertinência de pensar sobre esse indivíduo que se relaciona de diferentes maneiras com os seres e com o mundo invisível, ou seja, com uma cosmologia que se atualiza no presente e no corpo dessa pessoa assim construída. Nesses, a permeabilidade e a abertura para o outro são os definidores dessa identidade que se constrói, poderíamos dizer, nesse 'processo estrutural sincrético' para o qual Sanchis chama a atenção.

\section{REFERÊNCIAS:}

AMARAL, Leila. Carnaval da alma. Comunidade, essência e sincretismo na Nova Era. Petrópolis: Vozes, 2000.

ANJOS, José Carlos Gomes dos. No território da Linha Cruzada: a cosmopolítica afro-brasileira. Porto Alegre: Editora da UFRGS/Fundação Cultural palmares, 2006.

BIRMAN, Patrícia. Conexões políticas e bricolagens religiosas: questões sobre o pentecostalismo a partir de alguns contrapontos. In: Pierre Sanchis (Org.). Fiéis e Cidadãos. Percursos de Sincretismos no Brasil. Rio de Janeiro: Editora da UERJ, p. 59-86, 2001.

CHAMPION, Françoise. La croyance en l'alliance de la science et de la religion dans les nouveaux courants mystiques et ésotériques. In: Archives de Sciences Sociales des Religions, v. 82, avril-juin, 1993.

. Constituição e transformação da aliança ciência-religião na nebulosa mística esotérica. In: Religiāo e Sociedade. Rio de Janeiro: ISER, v. 21, n. 2, nov. 2001, p. 25-43.

GEERTZ, Clifford. A Interpretação das Culturas: Rio de Janeiro: Zahar Editores, 1978. 
GOLDMAN, Márcio. A construção ritual da pessoa: a possessão no Candomblé. In: Moura, C. M. (Org.). Candomblé. Desvendando Identidades. São Paulo: EMW Editores, p. 87-119, 1987.

MAUSS, Marcel. Uma categoria do espírito humano: a noção de pessoa, a de eu. In: Sociologia e antropologia. São Paulo: Editora Cosac \& Naify, 2003. RODOLPHO, Adriane Luisa. Entre a Hóstia e o Almoço: Um estudo sobre o sacrifício na Quimbanda. Porto Alegre: Universidade Federal do Rio Grande do Sul (Dissertação de Mestrado), 1994.

Seitas ou o mal à la francaise: reflexôes sobre as opções religiosas na sociedade francesa contemporânea. Debates do NER (UFRGS), Porto Alegre, v. 4, n. 4, p. 73-90, 2003.

- A Questão das Seitas na França: Vitalidade Religiosa de uma Mitologia Científica? REVER (PUCSP), v. 10, p. 57-79, 2007.

. Les Voyageurs de l'Âme. Étude Ethnologique auprès du Groupe Eckankar France - Paris. Sarrebruck: Éditions Universitaires Européennes, v. 1, 2010. 198'p.

SANCHIS, Pierre. Inculturação? Da cultura à identidade, um itinerário político no campo religioso: o caso dos Agentes de Pastoral Negros. In: Religião e Sociedade. Rio de Janeiro: ISER, v. 20, n. 2, out. de 1999. p. 55-72.

. Religiōes, religião... Alguns problemas do sincretismo no campo religioso brasileiro. In: Fiéis e Cidadãos. Percursos de Sincretismos no Brasil. Rio de Janeiro: Editora da UERJ, p. 09-57, 2001. 